\title{
Numerical investigation of the bearing capacity of transversely prestressed concrete deck slabs
}

\author{
S. Amir, C. van der Veen, J. C. Walraven \\ Department Design \& Construction, Structural and Building Engineering, Concrete section, Faculty of Civil \\ Engineering \& Geosciences, Delft University of Technology, The Netherlands.
}

A. de Boer

Ministry of Infrastructure and the Environment (Rijkswaterstaat), The Netherlands.

\begin{abstract}
The research subject of this paper is the bearing capacity of transversely prestressed concrete bridge decks between concrete girders under concentrated loads. Experiments on a 1:2 scale model of this bridge were carried out in the laboratory and a 3D nonlinear finite element model was developed in the FEA software package DIANA to study the structural behavior and investigate compressive membrane action in deck slabs. A comparative study of the numerical and the experimental results leads to the conclusion that existing bridges still have significant residual strength due to the presence of transverse prestressing and the membrane forces and non-linear FE models can predict the load carrying capacity quite accurately. A parametric study was also carried out and results are presented. It was observed that sufficient saving in cost can be made if calibrated numerical models are employed to investigate existing structures rather than doing expensive experimental studies.
\end{abstract}

\section{INTRODUCTION}

\subsection{Background}

One of the most important questions that designers all over the world are dealing with is the safety of the existing structures. In the Netherlands, there are a large number of transversely prestressed bridge decks that were built in the last century and need to be investigated for their remaining lifetime capacity, if any, against the modern traffic loads, which are higher than assumed in the original design. The shear capacity as prescribed by the codes is more conservative in the recently implemented EN 19921-1:2005 (CEN 2005) than in the former Dutch NEN code. As a result, many existing bridges are found to be critical in shear when assessed using the Eurocode. This paper describes the numerical research being carried out to investigate the capacity of a 1:2 scaled model of a bridge with a thin transversely prestressed concrete deck slab, cast between precast concrete girders subjected to concentrated loads. Experiments have also been performed in the Stevin II laboratory, Faculty of Civil Engineering and Geosciences, Delft University of Technology on the scaled model of such a bridge. A comparison of the nonlinear finite element analysis and the experimental program is made along with a parametric study. The objective is to investigate the bearing (punching shear) capacity and to study the effect of different parameters, like the transverse prestressing level (TPL), the type and position of the loading, the concrete strength and the fracture energy on the punching shear capacity.

\subsection{Compressive membrane action}

Traditional methods of bridge design were based on conservative flexural theories and it has been discovered that under concentrated wheel loads, the laterally restrained deck slabs mostly fail in punching shear rather than in flexural (Batchelor 1990, Fang et al. 1994). Such behavior is attributed to the development of compressive membrane forces in the deck slab. When a load is applied on a laterally restrained slab, its edges tend to move outside and the boundary elements produce a compressive membrane force in the plane of the slab enhancing the bearing capacity in both flexure and punching shear. This phenomenon is called compressive membrane action (CMA).

At present, codes like Eurocode 2 (2005) and ACI 318 (2005) do not consider CMA in their capacity formulae. However, there are some codes that do consider CMA for reinforced concrete only, like CSA: CHBDC (2005), the Transit New Zealand (2003) code and UK HA, BD81/02 (2002). This has been possible because CMA has been studied in detail for reinforced concrete deck slabs and, although only limited research was done on prestressed slabs it is to be expected that CMA will also exist in such slabs. As a result the in-plane forces arising from the combined action of prestressing and membrane forc- 
es will increase the bearing capacity to a large extent allowing thinner deck slabs to be applied with no problems of serviceability and structural safety.

\section{EXPERIMENTAL PROGRAM}

\subsection{Real bridge}

In a typical "approach" bridge, the deck slab is quite slender (200 mm thick) and is cast in-situ between the flanges of precast, prestressed concrete girders (3000 $\mathrm{mm}$ high and spaced at $2100 \mathrm{~mm} \mathrm{c} / \mathrm{c}$ ). The joints between the deck slab and girder flange indent to generate sufficient shear capacity. The regular reinforcement ratio of the deck slab is quite low as prestressing reinforcement in the transverse direction is present. The prestressing tendons in the slab are placed in the transverse direction at an average spacing of around $650 \mathrm{~mm} \mathrm{c} / \mathrm{c}$. In some places this spacing is $800 \mathrm{~mm} \mathrm{c} / \mathrm{c}$. Transversely prestressed end transverse beams are present at the supports, along with diaphragms at $1 / 3$ and $2 / 3$ of the $50 \mathrm{~m} \mathrm{span}$. The bridge decks have been cast with normal strength concrete; however, currently the concrete strength is considerably higher as a result of ongoing cement hydration during many years.

\subsection{Prototype of the bridge}

In order to simulate an actual bridge as closely as possible, a 1:2 scale was used to design the prototype. Figure 1 shows the prototype in the laboratory.

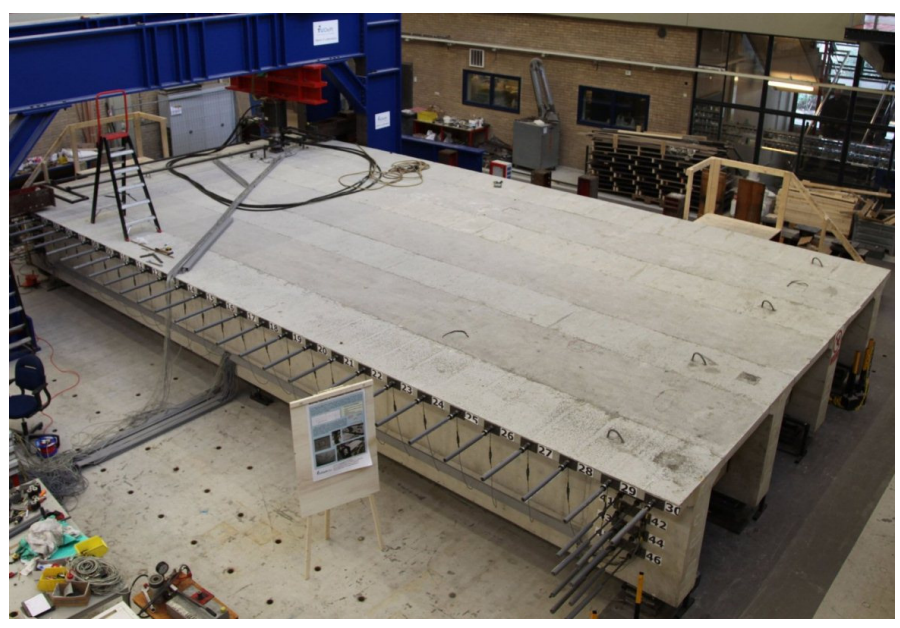

Figure 1. Pictorial view of the laboratory test setup.

The deck prototype was $12 \mathrm{~m}$ long (the span length was not scaled down and therefore no diaphragms were required for $12 \mathrm{~m}$ length) and $6.4 \mathrm{~m}$ wide consisting of four precast concrete girders placed at $1800 \mathrm{~mm}$ c/c distance (Fig. 2a, b). The exterior girders had an extended width of $125 \mathrm{~mm}$ at the exterior flanges to make sure that the prestressing and the confining effect was introduced adequately. The cross section of the girders is as shown in Figure 3. Some of the interfaces between the deck slab panel and the girder flange were skew (1:20) and their location in plan is shown in Figure 2a.

The deck slab was cast in-situ and post-tensioned in the transverse direction with a clear span of 1050 $\mathrm{mm}$ and had a thickness of $100 \mathrm{~mm}$. Regular steel reinforcement was provided at both top and bottom with $\Phi 6 \mathrm{~mm}$ bars at $200 \mathrm{~mm} \mathrm{c} / \mathrm{c}$ in the longitudinal direction and $\Phi 6 \mathrm{~mm}$ bars at $250 \mathrm{~mm} \mathrm{c} / \mathrm{c}$ in the transverse direction. The transverse prestressing steel consisted of $\Phi 15 \mathrm{~mm}$ unbonded bars posttensioned to the desired level. The interface between the slab and the girder was indented and had an inclination of $1: 20$.

The two transverse beams, $810 \times 350 \mathrm{~mm}$, were cast at $525 \mathrm{~mm}$ from each end of the bridge deck (Fig. 2a). The top of the transverse beams was at 190 $\mathrm{mm}$ from the top of the girders. The beams were reinforced with $\Phi 8 \mathrm{~mm}$ stirrups at $250 \mathrm{~mm} \mathrm{c} / \mathrm{c}$, and ten $\Phi 12 \mathrm{~mm}$ bars in four layers in the longitudinal direction. The prestressing consisted of $\Phi 15 \mathrm{~mm}$ bars in the transverse direction stressed to the same level as the deck slab.
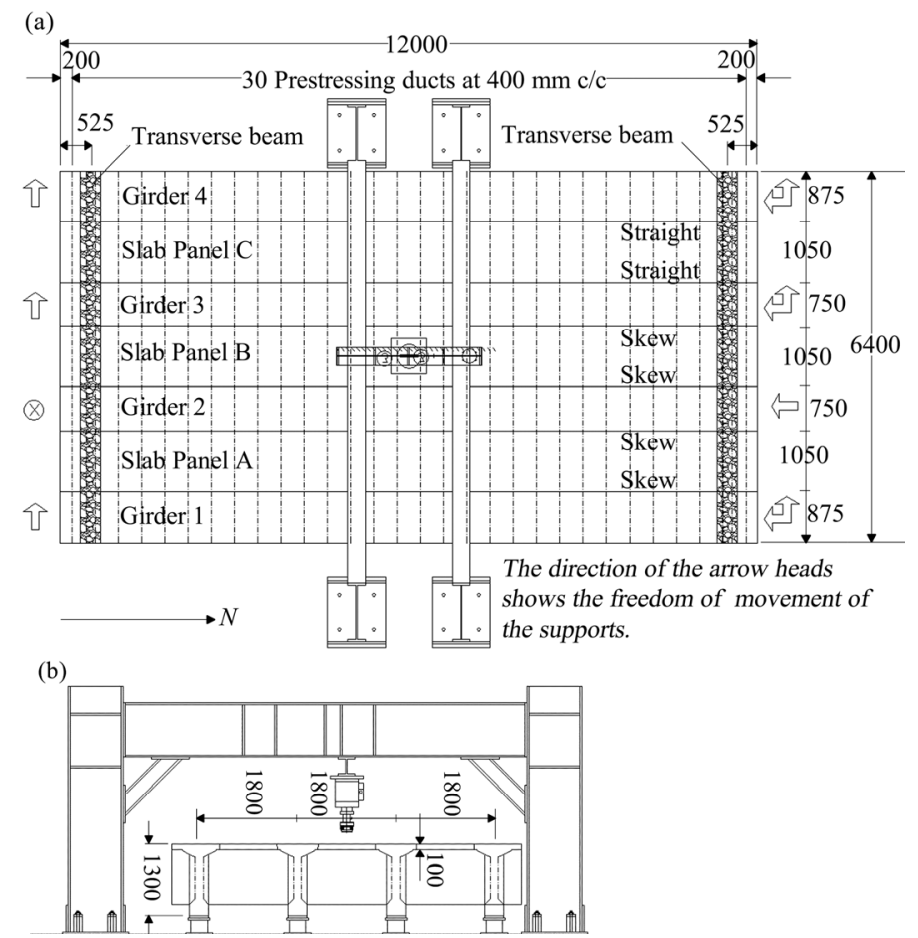

Figure 2. Test setup: a) Plan view b) Side view (transverse direction). All dimensions are in $\mathrm{mm}$.

\subsubsection{Material properties}

The concrete compressive strength was measured on cubes and converted to cylinder strength as per EC2 and the tensile strength was measured by splitting tensile strength test. For the deck slab and the transverse beams, the concrete compressive cylinder strength was $65 \mathrm{MPa}$, the tensile strength was 5.41 $\mathrm{MPa}$ and the modulus of elasticity, $\mathrm{E}_{\mathrm{c}}$ was calculated as $39 \mathrm{GPa}$ (Eurocode 2). For the girders, the concrete compressive cylinder strength was $75 \mathrm{MPa}$, the tensile strength was $6.30 \mathrm{MPa}$ and $\mathrm{E}_{\mathrm{c}}$ as per EC2 
was $41 \mathrm{GPa}$. The steel reinforcement had a yield strength of $525 \mathrm{MPa}$ and the prestressing steel had a characteristic tensile strength of $1100 \mathrm{MPa}$.

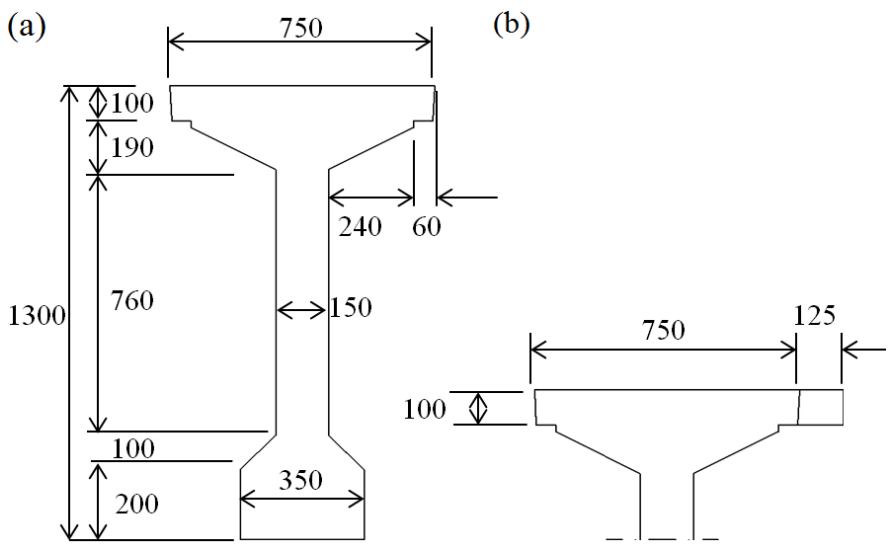

Figure 3. Cross section of prototype girder: a) Typical interior girder b) Extended width of $125 \mathrm{~mm}$ at the exterior flange of the exterior girder. All dimensions are in $\mathrm{mm}$.

\subsubsection{Type of the tests performed}

As shown in Figure 4, nineteen static tests were performed by applying a concentrated load simulating a single or double wheel print load through a hydraulic actuator attached to an overhead reaction frame bolted to the floor (Fig. 2). In all the tests, a concentrated load was applied through $200 \times 200 \mathrm{~mm}, 8$ $\mathrm{mm}$ thick, rubber bonded $200 \times 200 \times 20 \mathrm{~mm}$ steel plates.

Eight experimental cases and a parametric study will be discussed in this paper. For convenience, the following abbreviations will be used when referring to a particular test type.

- All the tests will be referred to as BB\#\# (test no).

- Point load acting at mid span of slab panel, P1M.

- Point load acting close to the girder flange-slab interface/joint, P1J.

- Two point loads at $600 \mathrm{~mm} \mathrm{c} / \mathrm{c}$ acting at mid span of slab panel, P2M.

- Two point loads at $600 \mathrm{~mm} \mathrm{c} / \mathrm{c}$ acting close to the girder flange-slab interface/joint, P2J.

- $\mathrm{M}=$ Midspan, $\mathrm{ST}=$ Straight joint, $\mathrm{SK}=$ Skewed joint, $\mathrm{J}=$ Joint/Interface, $\mathrm{AD}=$ Above Duct, $\mathrm{BD}$ $=$ Between the Ducts, TPL $=$ Transverse Prestressing Level.

The following are the salient features of the basic analysis:

- Two transverse prestressing levels were applied: 1.25 MPa and 2.5 MPa. A TPL of $0.5 \mathrm{MPa}$ was also applied in the bridge deck to serve as a control test.

- A single and a double load (with the spacing of $600 \mathrm{~mm} \mathrm{c} / \mathrm{c}$ ) were applied at the midspan of the deck slab.

- Two out of the three deck slab panels had skewed joints with the adjacent girder flanges. Therefore tests with single and double loads were also per- formed close to the skewed and straight interface. In almost all the tests, a load was applied at 200 $\mathrm{mm}$ from the interface $(\mathrm{c} / \mathrm{c})$, except for Test BB3 $\& 4$ with a TPL of 2.5 where the center of the loading plate was at $110 \mathrm{~mm}$ from the interface.

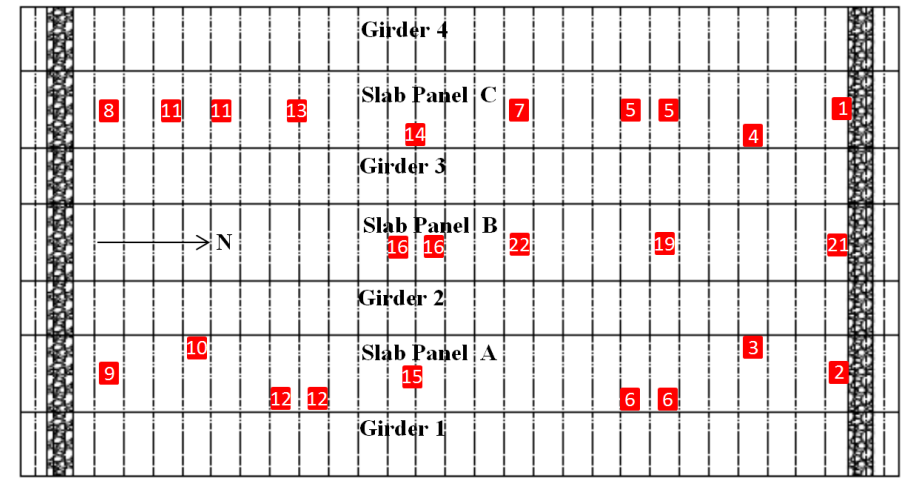

Figure 4. Deck slab test positions (BB1-BB22). Duct positions are also labelled.

\section{3D FINITE ELEMENT MODEL}

Most of the research work done in the past to study CMA in bridge decks has focused on experimental studies (Zheng et al. 2009). However, small scale testing does not necessarily depict true structural behavior because of the size effect and large scale testing is usually very costly. Therefore, it is essential that calibrated numerical models are developed that are able to predict the actual structural behavior, for e.g., the bearing capacity, load - deflection behavior, cracking pattern, compressive membrane action etc. Not only that, numerical models can be used to carry out a parametric study which may not be possible experimentally due to high costs associated with the construction and testing of physical models.

For the numerical analysis, a 3D solid finite element model of the prototype bridge deck (Fig. 5 \& 6) was made in the FEA software package DIANA $(\mathrm{FX}+9.4 .4)$. The model consisted of 3D solid elements (CHX60 and CTP45) with a fine mesh around the loading area and a course mesh away from the loading to reduce the time for computation. A layer of composed elements (CQ8CM) was provided in the fine mesh area to calculate compressive membrane forces. Ducts at $400 \mathrm{~mm} \mathrm{c} / \mathrm{c}$ were provided only in the fine mesh area around the loading. Prestressing pressure was applied according to the required level of transverse prestressing in the deck slab and the transverse beams.

For most cases the deck slab was analyzed nonlinearly while the girders and the transverse beams remained in the linear range. The only exceptions to this were the tests BB3 \& 4. The flange of the adjoining girder was analyzed as nonlinear since the load was too close to the interface $(110 \mathrm{~mm} \mathrm{c} / \mathrm{c})$ and linearity of the flange would have induced a much 
higher capacity than in reality. An embedded reinforcement grid based on the actual steel reinforcement ratio was provided in the deck slab panels at the top and bottom in the horizontal direction as well as the vertical direction.

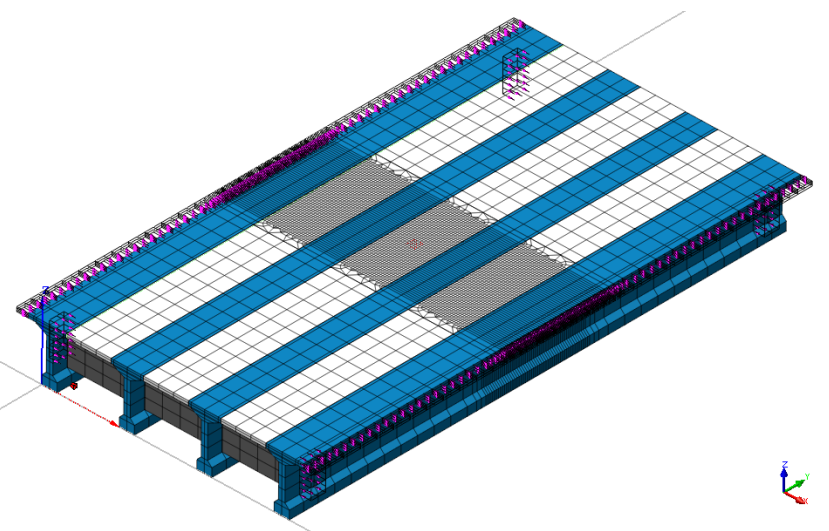

Figure 5. 3D solid finite element model developed in DIANA.

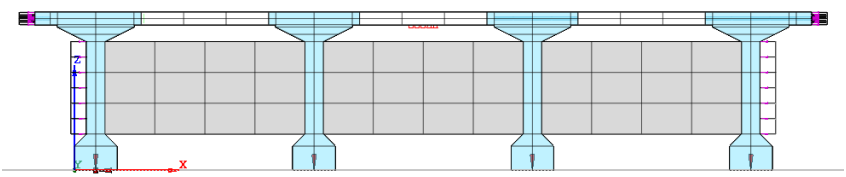

Figure 6. Cross-section of the 3D solid finite element model developed in DIANA.

\subsection{Material models and additional nonlinear material properties}

For the material properties of the girders and transverse beams that were analyzed as linear, reference is made to section 2.2.1. For the nonlinear analysis of the deck slab, a smeared cracking "Total strain crack rotating model" was selected. An elasticperfectly plastic model, CONSTA, was used for the concrete behavior in compression, whereas, an exponential softening curve, HORDIJK, (Hordijk 1990) was used for the concrete behavior in tension. A fracture energy $\left(\mathrm{G}_{\mathrm{f}}\right)$ of $0.15 \mathrm{~N} / \mathrm{mm}$ was assumed for the deck slab concrete (for a maximum aggregate size of $20 \mathrm{~mm}$, MC90 gives a value of $0.135 \mathrm{~N} / \mathrm{mm}$ for the fracture energy, whereas MC2010 gives a value of $0.21 \mathrm{~N} / \mathrm{mm}$ ). The poisson ratio, $v$, for all the concrete components, was taken as 0.2 . For the embedded grid reinforcement, the von Mises plasticity criterion was used with a poisson ratio of 0.3 .

\subsection{Iteration method and convergence criteria}

Both physical and geometrical nonlinearities were applied to the system. Composed elements were generated while giving the analysis commands. An incremental-iterative procedure was used for the nonlinear analysis and modified Newton Raphson method was used for the solution. The prestressing load was applied to the bridge deck in a single step. After that a displacement-controlled load was applied with a step size of $0.1 \mathrm{~mm}$ unless the solution diverged, in which case the displacement increment was reduced to $0.05 \mathrm{~mm}$. Since the applied load was displacement-controlled, the default force and energy based convergence criterion was employed.

\section{COMPARISON OF EXPERIMENTAL AND NUMERICAL RESULTS: BASIC ANALYSIS}

\subsection{Ultimate loads, cracking loads and cracking pattern}

In this section two modes of failure are distinguished; Brittle Punching and Flexural Punching. The ultimate loads with regard to the type of loading, position of the load and the transverse prestressing level (TPL) are collected in Figure 7a, b.
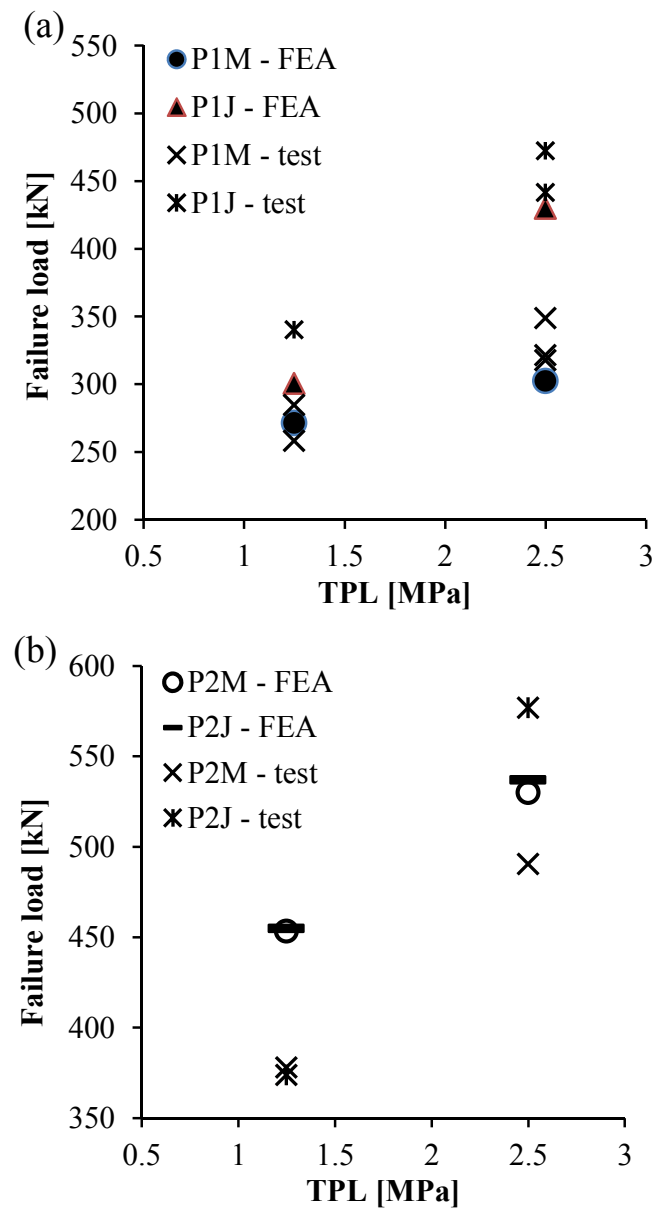

Figure 7. Comparison of experimental and FEA ultimate loads: a) Single load cases b) Double load cases.

It can be observed that an increase of the transverse prestressing level has a positive influence on the ultimate bearing capacity and double loads gave a higher capacity as compared to single loads. All these tests or FEA were performed in-between the prestressing ducts; hence the results represent a low- 
Table 1. Comparison of experimental and finite element results: Ultimate loads and cracking loads.

\begin{tabular}{|c|c|c|c|c|c|c|c|c|}
\hline \multirow[t]{2}{*}{$\mathrm{BB}$} & TPL & \multirow[t]{2}{*}{$\begin{array}{l}\text { Slab panel- } \\
\text { Test desig- } \\
\text { nation }\end{array}$} & \multirow{2}{*}{$\begin{array}{l}\text { Test ultimate } \\
\text { load }\left(\mathrm{P}_{\mathrm{t}}\right) \\
\mathrm{kN}\end{array}$} & \multirow{2}{*}{$\begin{array}{l}\text { FEA ultimate } \\
\text { load }\left(\mathrm{P}_{\text {fea }}\right) \\
\mathrm{kN}\end{array}$} & \multirow[t]{2}{*}{$\begin{array}{l}\text { Test mode of } \\
\text { failure }\end{array}$} & \multirow[t]{2}{*}{$\mathrm{P}_{\mathrm{fea}} / \mathrm{P}_{\mathrm{t}}$} & \multirow{2}{*}{$\begin{array}{l}\text { Test cracking load } \\
\text { (Initial }-0.1 \mathrm{~mm} \\
\text { width of crack) } \\
\mathrm{kN}\end{array}$} & \multirow{2}{*}{$\begin{array}{l}\text { FEA cracking } \\
\text { load } \\
\mathrm{kN}\end{array}$} \\
\hline & $\mathrm{MPa}$ & & & & & & & \\
\hline 1. & 2.5 & C-P1M-ST & 348.7 & 302.3 & Brittle punching & 0.86 & $75-150$ & 93.17 \\
\hline 2. & 2.5 & A-P1M-SK & 321.4 & 302.3 & Brittle punching & 0.94 & $75-150$ & 93.17 \\
\hline 3. & 2.5 & A-P1J-SK & 441.6 & 429.9 & Brittle punching & 0.97 & $75-175$ & 107.08 \\
\hline 4. & 2.5 & C-P1J-ST & 472.3 & 429.9 & Brittle punching & 0.91 & $100-175$ & 107.08 \\
\hline 5. & 2.5 & C-P2M-ST & 490.4 & 529.9 & Flexural punching & 1.08 & $150-200$ & 151.8 \\
\hline 6. & 2.5 & A-P2J-SK & 576.8 & 537.0 & Brittle punching & 0.93 & $150-250$ & 165.19 \\
\hline 7. & 2.5 & C-P1M-ST & 345.9 & 302.3 & Brittle punching & 0.87 & $75-125$ & 93.17 \\
\hline 8. & 1.25 & C-P1M-ST & 284.5 & 271.4 & Brittle punching & 0.95 & $50-100$ & 84.94 \\
\hline 9 & 1.25 & A-P1M-SK & 258.2 & 271.4 & Brittle punching & 1.05 & $50-100$ & 84.94 \\
\hline 10. & 1.25 & A-P1J-SK & 340.3 & 300.7 & Brittle punching & 0.88 & $25-100$ & 83.67 \\
\hline 11. & 1.25 & C-P2M-ST & 377.9 & 453.4 & Flexural punching & 1.20 & $50-125$ & 120.37 \\
\hline \multirow[t]{3}{*}{12.} & 125 & A-P2J-SK & 373.7 & 454.9 & Brittle punching & 1.22 & $100-175$ & 116.4 \\
\hline & & & & & Mean & 0.99 & & \\
\hline & & & & & St. deviation & 0.12 & & \\
\hline
\end{tabular}

* Refer to Figure $2 \& 4$ and section 2.2.2 for slab panel numbers and tests designations.

** The test cracking loads are subjected to the load step used (in multiples of 25 or $50 \mathrm{kN}$ ) and the FEA cracking loads are subject to the displacement load step size used.

er bound of the bearing capacity. Generally speaking, the governing mode of failure was brittle punching except when a double load was applied at midspan of the deck slab panel resulting in a flexural punching mode of failure. Also, failure always occurred within the span of the slab in all the cases.

\subsubsection{Brittle punching failure}

When a single load was applied at the slab midspan or when a single or double load was applied close to the interface, brittle punching failure was observed in both the experiments and FE simulations (Figure $7 \mathrm{a}, \mathrm{b})$. Generally the FEA results for brittle punching were conservative with the exception of the 1.25 $\mathrm{MPa}, \mathrm{P} 2 \mathrm{~J}$ case, where the numerical ultimate load was found to be 1.22 times the test ultimate load. For the $1.25 \mathrm{MPa}, \mathrm{P} 1 \mathrm{M}$ case, the FE ultimate load lies within the experimental scatter and for the rest of the single load cases, the FE ultimate loads were well below the test values.

\subsubsection{Flexural punching failure}

When a double load was applied at the slab midspan flexural punching behavior was observed. Such failures in the experiments were associated with large rotations occurring during loading and the substantial widening of a single longitudinal crack when approaching failure. However, the final failure still occurred according to the punching mode. The calculated FEA ultimate loads for $1.25 \mathrm{MPa}$ and 2.5 $\mathrm{MPa}(\mathrm{P} 2 \mathrm{M})$ are 1.20 and 1.08 times the test ultimate loads respectively.

\subsubsection{Cracking loads}

The initial cracking load characterized by hairline cracks and the cracking load defined at $0.1 \mathrm{~mm}$ wide cracks (first significant cracks) are given in Table 1 and compared with the finite element initial cracking loads. The FEA cracking loads show good correlation with the experimentally observed values and fall somewhere between the initial hairline and 0.1 mm cracking loads. As expected, a higher TPL delayed cracking and double loads and loads close to the support/interface showed higher cracking loads as compared to the single loads and loads at the midspan of the deck slab panel, respectively.

\subsubsection{Cracking pattern}

For the tests with a single load applied at midspan and close to the support/interface, the initial cracks initiated directly under the loading plate at the bottom side of the deck slab as shown in Figure 8. At higher load levels, radial/diagonal cracks were observed which propagated and widened further as the load increased. Circumferential cracks were observed close to failure during the tests but not in the FEA. A punching cone was observed at failure.

For the double load tests carried out close to the joint/interface (P2J), a similar cracking pattern was observed in tests and FEA. As expected, the cracks were clustered more towards the area of load application. A punching cone was observed at failure and no damage to the interface was observed except for some spalling of the bottom concrete cover of the flange at the failure stage.

For the P2M cases, initial cracks were observed directly under the loading plate; subsequently a longitudinal crack joined the two loading points at the bottom side of the deck slab. As the load increased these cracks increased in width and radial cracking was initiated and also observed at both loading points. Failure, however, finally occurred due to punching of one of the loading plates. 


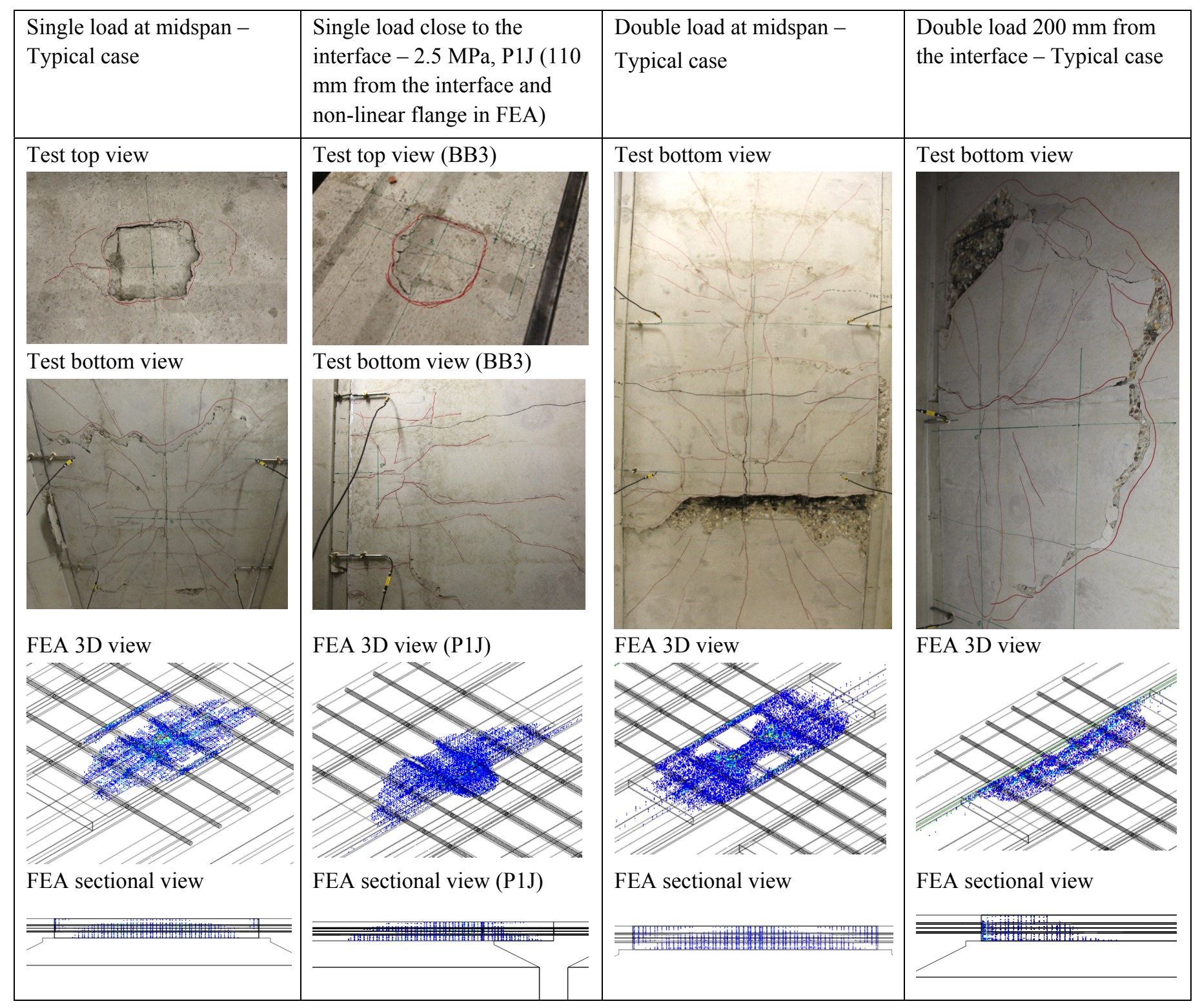

Figure 8. Comparison of experimental and finite element results: Cracking pattern.

In the FEA, the longitudinal strip between the two loading points showed a band of cracking and radial cracking and simultaneous punching was observed at both points.

\section{NUMERICAL PARAMETRIC STUDY}

A detailed numerical parametric study was also carried out as part of this research. Comparison with the experimental results was made where available. The effect of the following parameters will be discussed in this paper.

- Transverse prestressing level (TPL): 0.5, 1.25, 2.5 and $4.5 \mathrm{MPa}$.

- Loading interior and exterior deck slab panels.

- Loading above or in-between the ducts.

- Fracture energy: $0.13 \mathrm{~N} / \mathrm{mm}$ and $0.175 \mathrm{~N} / \mathrm{mm}$.

- Concrete class: Normal strength concrete and high strength concrete.

- Observations from the basic analysis.

\subsection{Transverse prestressing level}

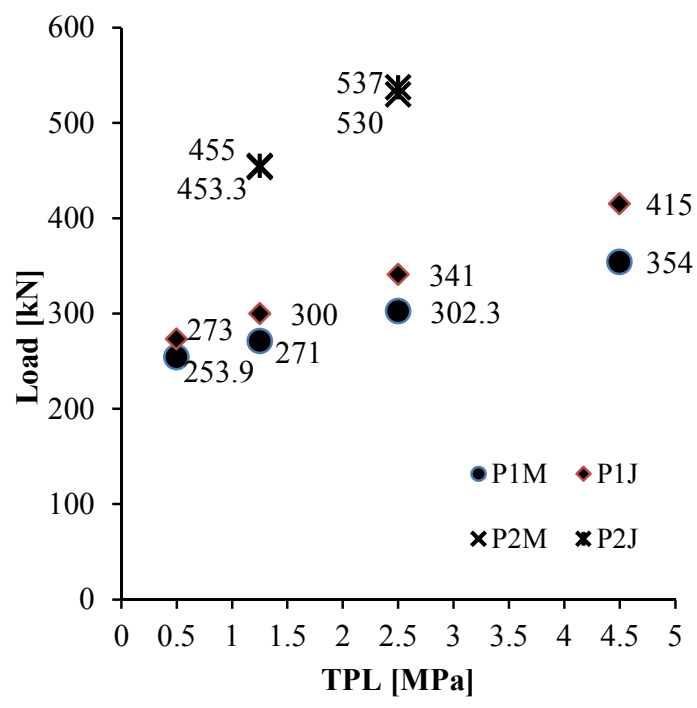

Figure 9. Variation in the transverse prestressing level in FEA. The ultimate loads are labelled w.r.t the particular data point. 
The transverse prestressing level was varied to study its effect on the punching shear capacity. All other parameters remained the same as in the basic analysis. A single load was applied at the midspan and at $200 \mathrm{~mm}$ to the interface (c/c distance) and the TPL was varied between 0.5 to $4.5 \mathrm{MPa}$. Also a double load was applied at the midspan and at $200 \mathrm{~mm}$ to the interface (c/c distance) for 1.25 and $2.5 \mathrm{MPa}$.

It was observed during the basic analysis that increasing the TPL increased the punching shear capacity of the deck slab (Figure 7). This observation was vindicated by increasing the number of prestressing levels and observing the same tendency. The cracking loads shown in Table 1 also indicate an increase in the initial cracking loads with higher TPLs.

\subsection{Load position with regard to deck slab panels:} Interior and exterior position
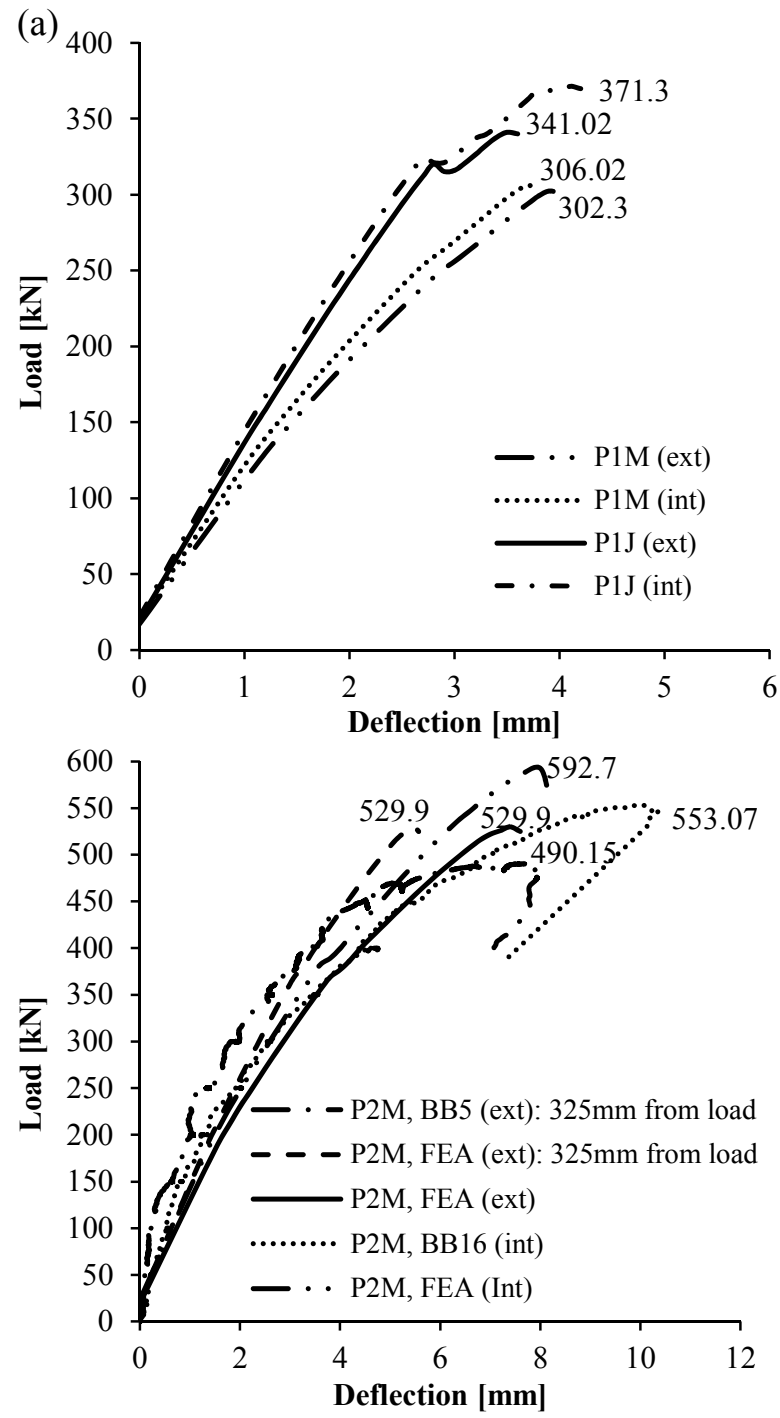

Figure 10. Loading interior and exterior slab panels (TPL 2.5 $\mathrm{MPa}$ ): a) Load type P1M and P1J b) Comparison of FEA and test results for load case $\mathrm{P} 2 \mathrm{M}$.

Figure 10 shows the effect of loading interior or exterior panels for a particular load type. The TPL used for the analysis was $2.5 \mathrm{MPa}$. All other parameters remained the same as in the basic analysis. Figure 10a shows $\mathrm{P} 1 \mathrm{M}$ and $\mathrm{P} 1 \mathrm{~J}$ applied at interior or exterior panels. It can be observed that for P1M, interior and exterior deck slab capacities are almost equal whereas for P1J, the capacity of the interior panel is 1.08 times that of the exterior panel. Figure $10 \mathrm{~b}$ shows the double load applied at interior and exterior panels (P2M load case). Both experimental and numerical capacity of interior deck slab panel is 1.13 times that of the exterior deck slab panel. It can also be observed that the stiffness of interior and exterior deck slab panels in all load cases is fairly comparable. Since there is no significant difference between the capacity of interior and exterior deck slab panels, this factor can be ignored.

\subsection{Loading above or in-between the ducts}

Most of the tests and FEA were performed by loading in-between the ducts. Previous research by $\mathrm{He}$ (1992) on a prestressed deck indicated that loading above a prestressing wire could influence the load deflection behavior positively. Hence, the influence of the loading position with regard to the ducts was investigated experimentally and numerically.

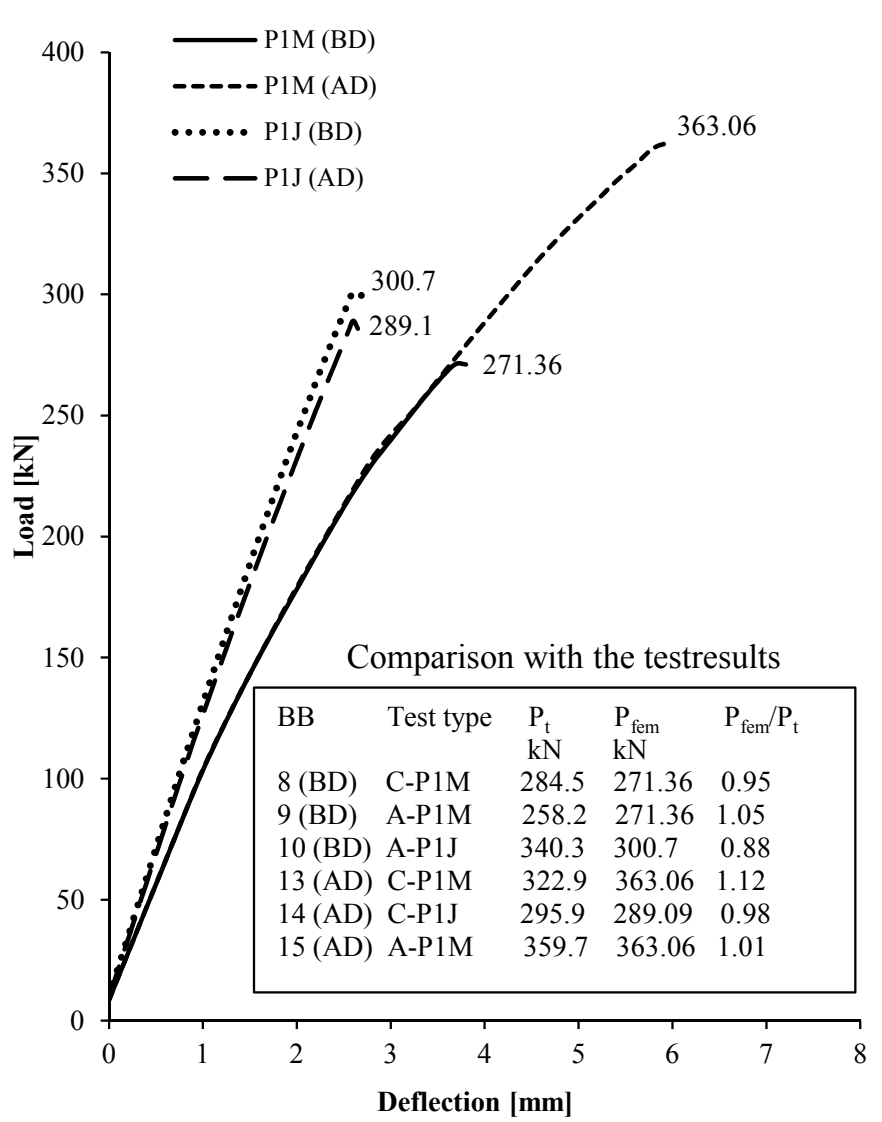

Figure 11. Effect of the loading position w.r.t the ducts (P1M and P1J applied with a TPL of 1.25 MPa for this analysis). BD and $\mathrm{AD}$ indicate in-between or above the ducts respectively.

The FEA results show that when the load was applied at the midspan and above a duct, the deck slab 
failed at higher loads compared to when the same load was applied in-between two ducts. The interface tests showed no significant difference between the two loading positions. Experimentally, for the midspan tests, the same result was obtained, i.e. a higher capacity when loading above the ducts, however, for the interface tests, a lower capacity was obtained when the deck slab panel was loaded above the duct. This discrepancy can be explained by the fact that the test BB14 (showing a lower than expected capacity) was the last test performed on the panel $\mathrm{C}$ which was severely damaged by previous tests. The FEA simulation for this test did not include previous damage effects. It can be concluded that the deck slab shows a higher capacity when loaded directly above a prestressing duct. Since, most of the analyses were performed in-between the prestressing ducts, hence the results of this research represent a lower bound of the bearing capacity.

\subsection{Fracture energy, $G_{f}$}

The influence of the fracture energy, $\mathrm{G}_{\mathrm{f}}$, on the ultimate capacity of the model bridge deck was determined by carrying out analyses with $0.13 \mathrm{~N} / \mathrm{mm}$ and $0.175 \mathrm{~N} / \mathrm{mm}$ fracture energy, whereas, the value used generally in all the FE analysis was 0.15 $\mathrm{N} / \mathrm{mm}$. All other parameters remained the same. It was important to study the influence of $\mathrm{G}_{\mathrm{f}}$ on the capacity of the deck slab since there is a difference between the theoretical determination of fracture energy by using Model Code 90 (1993) and Model Code 2010 (2012). MC90 gives lower values while MC2010 gives much higher values of the fracture energy for the same concrete strength and aggregate size.

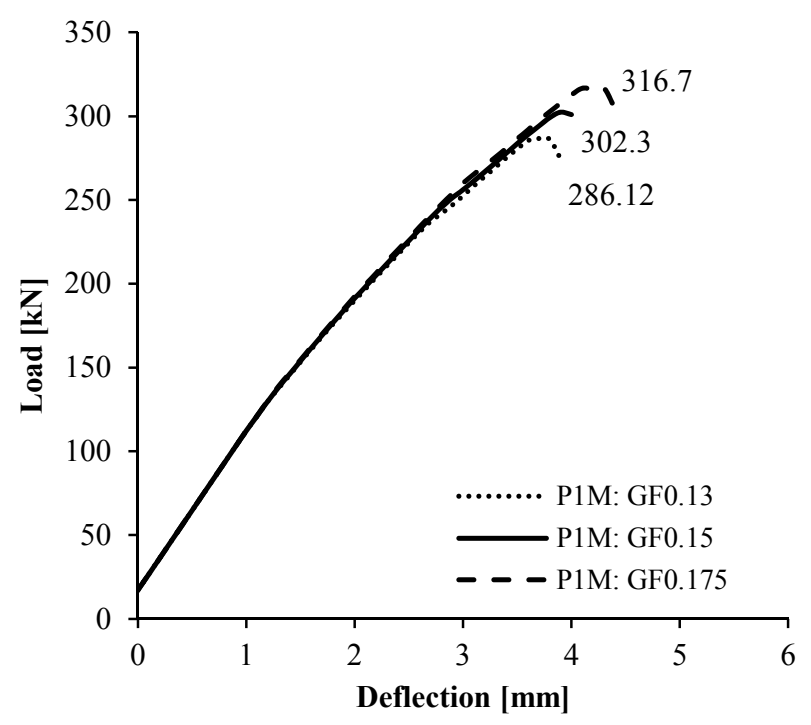

Figure 12. Influence of the fracture energy on the ultimate bearing capacity of the model bridge deck (P1M was applied with a TPL of 2.5 MPa for this analysis).

Figure 12 shows that although there is no difference in the initial stiffness of the deck slab for the three levels of $\mathrm{G}_{\mathrm{f}}$ checked for the analysis $(0.13$, 0.15 and $0.175 \mathrm{~N} / \mathrm{mm}$ ), the deformation capacity of the deck slab increases with increasing the fracture energy. As a result the ultimate bearing capacity (punching shear in this case) also increases. This correlates well with the observations made by Hallgren (1996).

\subsection{Concrete class}

The influence of the concrete strength was studied by varying the important material properties of the concrete like the compressive strength, the tensile strength and the fracture energy. A normal strength concrete (NSC) with a mean compressive cylinder strength of $50 \mathrm{MPa}$, mean tensile strength of 4.5 $\mathrm{MPa}$ and a fracture energy of $0.13 \mathrm{~N} / \mathrm{mm}$ and a high strength concrete, HSC1 (Hallgren 1996) with a mean compressive cylinder strength of $91.3 \mathrm{MPa}$, mean tensile strength of $6.21 \mathrm{MPa}$ and a fracture energy of $0.179 \mathrm{~N} / \mathrm{mm}$ was used. The control analysis case was for the concrete strength as used in the laboratory tests as the basic finite element analysis. All other parameters (loading type, TPL etc. remained the same).

Figure 13 shows that the ultimate bearing capacity of the deck slab has a direct relation with the concrete strength. Using a higher concrete class improves the punching shear capacity although the response is stiffer and a more brittle behavior is observed. However, it was observed as well that the increase in capacity was not linear and perhaps the increasing brittleness with the higher concrete strength is the reason behind that. A similar observation was made by Hallgren (1996) in his $\mathrm{PhD}$ thesis.

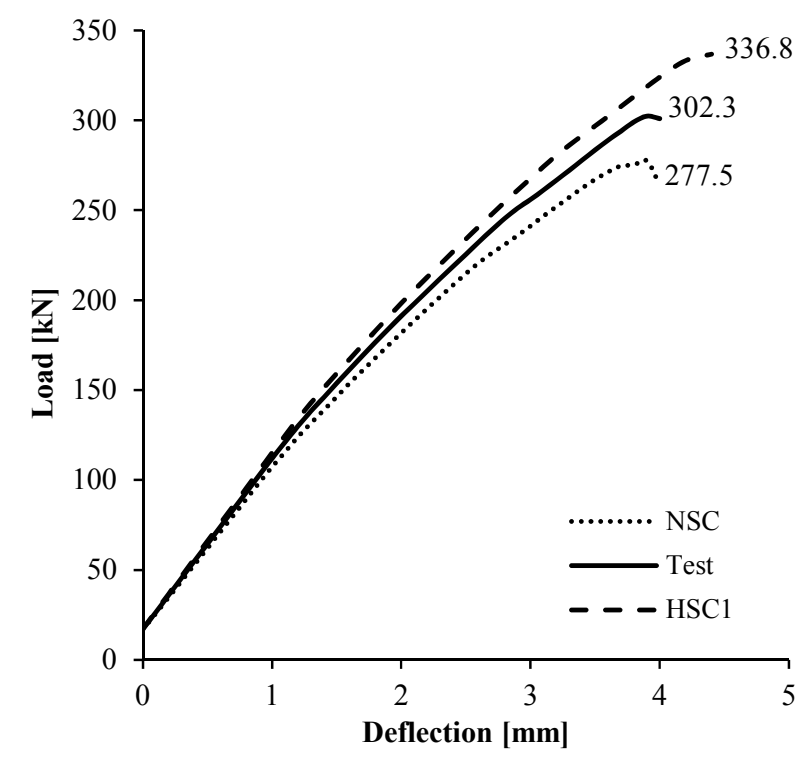

Figure 13. Influence of the concrete strength on the ultimate bearing capacity of the deck slab (P1M applied with a TPL of $2.5 \mathrm{MPa})$. 


\subsection{Observations from the basic analysis}

Some observations from the basic analysis are summarized as follows:

- For a single load case, a higher punching shear strength is observed when the load is acting close to the interface as compared to when the load is acting at midspan of the deck slab panel.

- For a double load case, the capacity at the interface and midspan remains almost equal owing to the flexural action that increases the capacity when loading at midspan.

- Regardless of the position of the load, whether it is at midspan or close to the interface, failure always occurs within the span of the slab.

\section{COMPRESSIVE MEMBRANE ACTION}

It is evident from the experimental and finite element analysis results that sufficient membrane action had developed in the plane of the deck slab and combined with the transverse prestressing, it positively enhanced the ultimate bearing capacity of the deck slab. It was observed both experimentally and numerically that for each type of the load, the deck slab showed horizontal or lateral displacements only after the initial cracking which correlates well with the findings of Liebenberg (1966), Fang (1985) and He (1992).

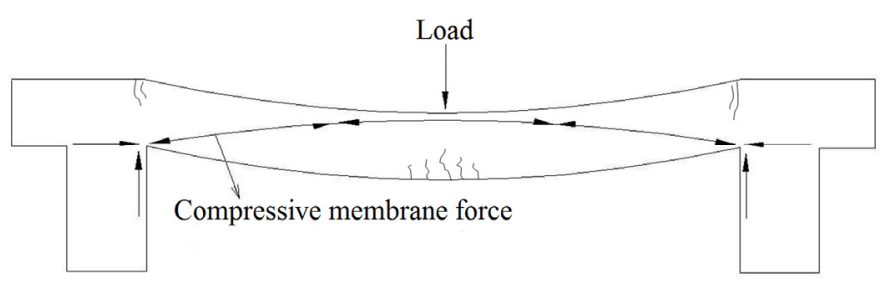

Figure 14. CMA develops after initial cracking and forms an arch shape within the plane of the laterally restrained slab.

Figure 14 shows compressive membrane action in theory. In FEA, the development of the in-plane forces around the loading area for load case P1M (single load at midspan) with respect to various transverse prestressing levels is as shown in Figure 15. The in-plane or compressive membrane force (in $\mathrm{N} / \mathrm{mm}$ ) initiates with the level of TPL applied to the bridge deck and remains almost unchanged until the initial cracking load (for e.g. $91.3 \mathrm{kN}$ cracking load for a TPL of $2.5 \mathrm{MPa}$ ). At first it develops gradually but then increases rapidly with the increasing load until failure. The in-plane forces correspond to the element right across the loading point having the maximum in-plane force.

Figure 16 shows the distribution of the normal stresses in the transverse direction at the failure stage. The membrane action developed is quite evident from the stress distribution diagrams showing the arching action being formed in the plane of the slab.

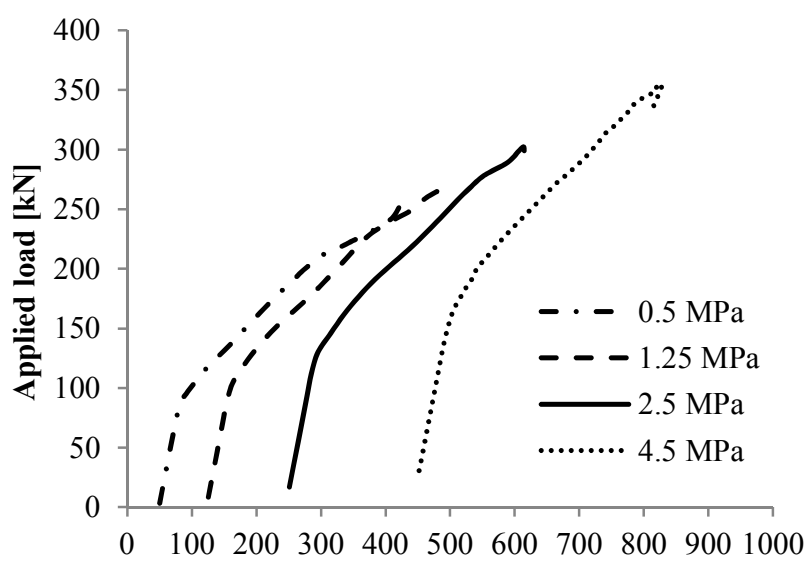

In-plane force $[\mathbf{N} / \mathbf{m m}]$

Figure 15. Development of in-plane forces (compressive membrane forces, CMF) w.r.t the applied load for the load case P1M with various TPLs. Load case 1 was prestressing pressure. Load case 2 was displacement-controlled incremental load.
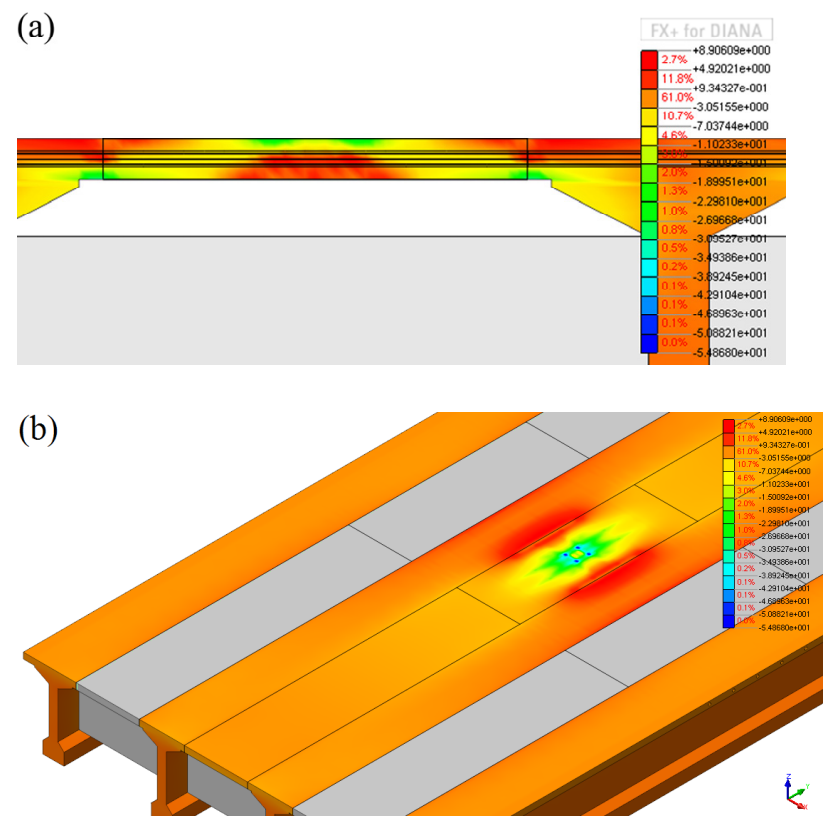

Figure 16. Transverse stresses in the cross-section (a) and 3D view (b) of the deck slab at failure stage (1.25 MPa, P1M load case)

Figure 17 shows the relationship between the distributed in-plane force developed $(\mathrm{N} / \mathrm{mm})$ and the failure load $(\mathrm{kN})$ for various levels of transverse prestress (MPa). It can be observed that the overall inplane force increases with the increasing prestress and the relationship is almost linear. However, subtracting the initial prestress from the overall in-plane force corresponding to that particular TPL gives a constant value of the compressive membrane force $(\mathrm{CMF} \sim 370 \mathrm{~N} / \mathrm{mm})$ for the deck slab showing that CMA is independent of the transverse prestress level. This would mean that for a particular deck slab 
having a certain lateral stiffness, the membrane action developed remains constant if all other parameters remain the same.

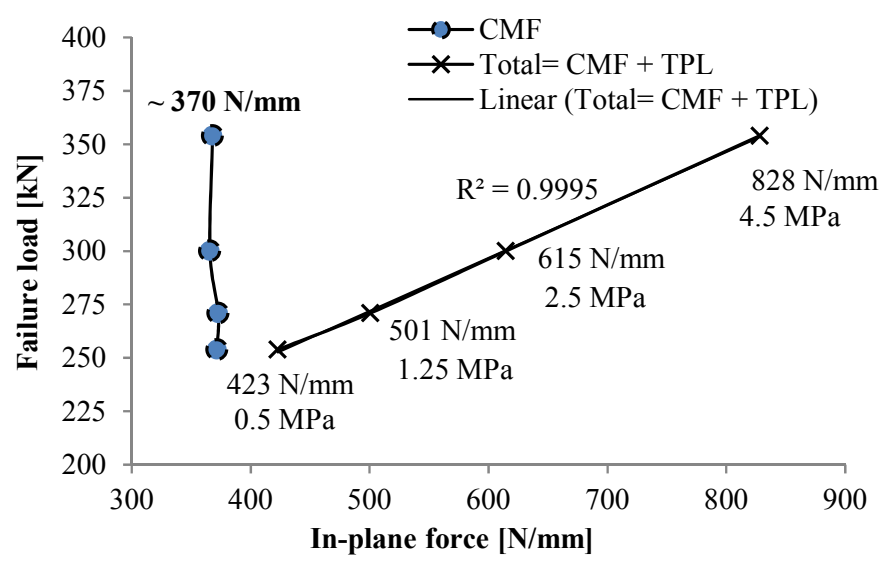

Figure 17. Relationship between the failure load and the inplane forces for various TPLs.

\section{SUMMARY AND CONCLUSIONS}

A 3D, solid, 1:2 scaled model of a real bridge was developed in the finite element software DIANA and non-linear analyses were performed to simulate the experiments done in the laboratory on the same prototype. A basic analysis comprising of eight test cases and a parametric study were performed to study the influence of various factors on the ultimate bearing capacity of the bridge deck. The detailed research results have led to the conclusion that the conventional bridge deck design and analysis methods are quite conservative and existing bridge decks have sufficient residual strength available to satisfy the modern traffic demands.

The following conclusions can be drawn from the research program:

- A substantial CMA develops in the deck slab and transverse prestressing affects the bearing capacity positively.

- The deck slab panels failed in punching shear rather than flexure due to compressive membrane action. This is in agreement with the findings of other researchers (Batchelor 1990, Kirkpatrick et al. 1984) that the governing mode of failure for restrained slabs and deck slabs is not flexure but punching shear.

- Failure always occurs in the deck slab span, regardless of the position of the load and the interface has proven to have sufficient strength and is never critical.

- The level of transverse prestressing affects the cracking behavior. The higher the TPL, the higher was the initial cracking load.

- When loaded directly above a prestressing bar/duct, the deck slab shows a higher punching capacity. Since most of the analyses were per- formed with loads applied in between the ducts, the results are on the conservative side.

- Punching shear failures can be reasonably modeled with non-linear finite element analysis of 3D solid models. Furthermore, using composed elements can lead to the determination of compressive membrane forces developed in a laterally restrained slab, which were previously difficult to determine using analytical techniques.

\section{REFERENCES}

ACI Committee 318 (2005), Building Code Requirements for Structural Concrete (ACI 318-05) and Commentary (318R05). Farmington Hills, Michigan: American Concrete Institute.

Batchelor, B. de V. 1990. Membrane Enhancement in Top Slabs of Concrete Bridges, Concrete Bridge Engineering, Performance and advances: 189-213. London: Routledge.

Canadian Standard Association: Canadian Highway Bridge Design Code (CHBDC), CAN/CSA-S6-00 (R2005), Canada.

CEN. 2005. Eurocode 2: Design of Concrete Structures - Part 1-1 General Rules and Rules for Buildings. NEN-EN 19921-1:2005. Brussels, Belgium: Comité Européen de Normalisation.

DIANA. 2012. User's Manual - Release 9.4.4. Delft: TNO Building and Construction Research.

Fang I.K. 1985. Behavior of Ontario-Type Bridge Deck on Steel Girders. PhD. Dissertation. Austin: University of Texas.

Fang, 1. K., Lee, J. H., \& Chen, C. R. 1994. Behavior of partially restrained slabs under concentrated load. ACI Struct. Journal 91 (2): 133-139.

Hallgren, M. 1996. Punching shear capacity of reinforced high strength concrete slabs. PhD Dissertation. Stockholm: Royal Institute of Technology.

He, W. 1992. Punching behavior of composite bridge decks with transverse prestressing. PhD Dissertation. Ontario: Queen's University.

Hordijk, D. A. 1991. Local Approach to Fatigue of Concrete. PhD Dissertation: Delft: Delft University of Technology.

Kirkpatrick, J., Rankin, G. I. B. \& Long, A. E. 1984. Strength of Evaluation of M-Beam Bridge Deck Slabs, Structural Engineer 62b (3): 60-68.

Liebenberg, A. C. 1966. Arch action in concrete slabs. CSIR Research report (234). Bulletin 40. Pretoria: National Building Research Institute.

MC 90. 1993. CEB-FIP Model Code 1990. London: Thomas Telford Ltd.

MC 2010. 2012. Fédération Internationale du Béton (fib) Model Code 2010. Final draft (1). Bulletin 65. Lausanne.

NEN 6720:1995. Regulations for concrete: structural requirements and calculation methods (in Dutch). Dutch Normalisation Institute (NEN).

Transit New Zealand Ararau Aotearoa. 2003: New Zealand Bridge Manual (2nd Ed).

UK Highways Agency, BD 81/02. 2002. Use of Compressive Membrane Action in bridge decks. Design Manual for Roads and Bridges 3.4 (20).

Zheng, Y., Taylor, S., Robinson, D., \& Cleland, D. 2010. Investigation of Ultimate Strength of Deck Slabs in SteelConcrete Bridges. ACI Structural Journal 107(1): 82-91. 